laten aan partijen zelf of aan raadslieden, die uit hoofde van hun beroep in zulke omstandigheden niet onpartijdig behoeven te zijn. De eigenlijke belangenstrijd immers kan niet objectief worden gevoerd. Fin hij behoeft ook niet objectief te worden gevoerd; want 't is het goed recht van een ,partij"', indien zij eenmaal van de juistheid van haar zienswijze overtuigd is, met kracht van argumenten voor die zienswijze te strijden. Het is praktisch onmogelịk, daarbij als partij ook de tegenargumenten aan te voeren en te wegen; dat verwacht de praktijk ook niet van een ,partij"'. En daarom wordt de aanwezigheid van den accountant of de vertegenwoordiging door den aceountant bijj dien strijd, cen hindernis voor de eigen partij en voor den accountant, die steeds weer genoopt wordt tot ingrijpen in den strijd, tegen de argumentatie van den eigen cliënt in, wil hij niet door zijn stilzwijgen zijn objectiviteit verspelen.

In de gestelde vraag wordt intussehen de aanwezigheid van den accountant verondersteld; en ongetwijfeld brengt de praktijd herhaaldelijk mede, dat de accountant zich in 't belang van zijn cliënt niet daaraan kan onttrekken. Zijn aanwezigheid hrengt trouwens ook roordeel voor beide partijen, omdat hij met zijn toelichting en zijn raad als onpartijdig deskundige de onderhandelingen kan bevorderen en de kans op cen juist resultaat ervan kan verglooten. Maar dan staat alweer vast, dat zijn arbeid ook de beteekenis ontleent aan zijn onpartijdigheid en daarmede dus ook, dat zijn aanwezigheid hem meer dan ooit den plicht der objectiviteit oplegt.

TH. L. Jr.

\section{STATISTIEK EN BEDRIJFSLEIDING}

De statistiek is een van cle hulpmiddelen, welke de bedrijfslciding in staat stellen, haar taik succesvol te volbrengen.

Voor overschatting van het instrument der statistiek, in dit opzicht, moet echter gewaakt worden.

Gaan we immers den inhoud van de statistiek na, dan is het. nicts dan en methode tot onderzoek van massagegevens, ten einde hieruit eenc algemeene bewegings- of ontwikkolingsi ijn vast te stellen.

De methode der statistiek werkt dus vergelijkend en om dit te mogen doen, moet ze gelijksoortige en gelijkwaardige gegevens vergelijken.

Dat de statistiek dit niet altijd doet is onbetwistbaar.

Nemen we als voorbeeld de statistiek als methode van onderzoek op sociaal-economisch terrein.

We zien dan h.v. indexcijfer-vergelijking.

Wat een indexcijfer is mogen we bij de(n) lezer(es) bekend veronderstellen.

Nu worden indexeijfer's, watrbij als basis genomen is 1913 , vergeleken met elkaar.

Hierdoor hegaan we echter de fout, niet, te letten op de ontwikkeling, die de maatschappij, doormaakte vanaf 1913.

Zou, bij gelijke prijzen als in 1913, een indexcijfer van heden even loog uitvallen als in 1913 ?

Zeer zcker niet, want de samenstelling der cijfers, is gelsecl ver'underd, in verband met de matschappelijke behoeften.

Om dus vergelijkbaar te zijn met 1913 zouden we met vele andere factoren nog rekening moeten houden.

Het Neulcl. Centraal Bureau roor de statistiek boweegt zich reeds sedert lang in deze richting.

Ook buitenlandsehe słatistiek bureaux doen dit. Dit was een roorbecld genomen uit de algemeen-conomische statistiek.

Ook op het gebied der privaat-conomische statistiek, de in terne bedrijfsstatistiek, bestaan zulke voorbeelden. Nemen we cens een verandering in de productiewijze aan.

Zijn de cijfer's dan zonder meer vergelijkbaar?
Ook hier moeten we, in zoo ecn geval, rekening houden met veranderde factoren, met factoren, die bij de eerste opstelling niet moewerkten, doch welke op latere cijfers eerst hun invloed deden gelden. Vergelijking zonder' meer zou tot geheel ver'lieerde conclusies leiden.

We spraken daar zoocven van algemeen cconomische statistiek en van privat-economische statistiek, wolke laatste we ook interne statistick noemden, waaltegenover we dan de eerstgenoemde, externe statistiek zouden kumnen noemen.

Wij verkiczen echter te spreken vau algemeen economische statistick als de statistick van het sociaal-economische leven, waartegenover wij stellen de privaateconomische statistiek, als de statistiek, niet over maar in het bedrijfsleven, welke we splitsen in cene externe en eene interne statistiek; de eerstgenoemde is dan te omschrijven als de statistick over de voorvallen in de onderneming welke van buitenaf ontstaan zooals, verkoopstatistieken, debiteurenstatistieken, en andere statistie$\mathrm{kcn}$ toegepast op verschijnselen betreffende de werking der onderneming op de samenleving en omgekeerd, terwijl de interne statistiek dan die statistiek is, welke verschijnselen behandelt binnen de grenzen der onderneming, zooals productiviteitsstatistieken, loonstatistieken en dergl.

Hen juiste splitsing tusschen de algemeen en de privaat-economische statistiek is noodig op grond van het groote verschil tusschen de beschikbare gegevens. De statistische methode in hadr eigenlijke beteckenis, is een zeer ruw instrument, hetwelk zijn warde ontleent aan het groote aantal verschijnselen, dat zij in haar kring betrekt.

Zij berust geheel op de wet der groote getallen.

Uit den aard der zalak kan nu de algemeen economische statistiek beter aan dit vereischte, methodische boekhouding over, voor massale waarneming vatbare, levensverschijnselen, beantwoorden. De privaat-economische statistiek beschikt altijd over veel minder gegevens, zoodat de relatieve fout, bij onnauwkeurigheden, hier direet veel en veel grooter wordt. In verband hiermede zal de samenstelling der privaat-economische statistiek een grootere mate van nauwkeurigheid eischen, wil zij aan haar doel kummen beantwoorden.

J)armaast is tusschen de twee nog een zeer groot verschil, 11.l., wil de privaat-economische statistick nuttig zijn, dan zal zc over veel kortere periodes moeten worden samengesteld, zal meestal moeten worden uitgebouwd tot een doorloopende statistische boekhouding, waarbij het hoofddoel, zooals bij de algemeen economische statistiek, nict bestaat in de verzameling der gegevens, maar in de opstelling der gegevens, zoodat uit de boekhouding zonder meer, reeds direct conclusies kumnen worden getrokken. Bij de algemeen economische statistiek worden daartoe de gegevens der boekhouding eerst nog in ecn bepaalde grocpeering gebracht. De inhoud van den vol'm van de statistick is dus geheel anders.

J)a anlaast staat nog, dat de algemeen economische statistiek, in het bijzonder zich bezig houdt met het onderzoek naar een ontwikkcling het vroeger genoemde voornaamste doel; van de privaat-economische statistiek wordt echter', niet alleen een ontwikkelingslijn, maar een voorstelling gevraagd van voorvallen zolf, in het bizonder, b.v. de voorstelling van de productiviteit van één arbeider op één bepaalde machine, voor één bepaald product.

Of we hiermede buiten het bereik del" statistiek gaan, zou cen vraagpunt kunnen zijn; o.i. echter, wanneer we het begrip in zijn ruimste beteekenis nemen, niet.

Tegen het nemen van een rumere beteekenis bestalan dikwijls bezwaren, ondat zij soms de grenzen van het tejrein uit het oog doct velliezen.

1)it bezwaar' zal echter hier niet van groot bclang zijn, daar het hier slechts aankont op de toepassing eener methode. 
Bovendien, ook de chemische wetenschappen, de geneeskunde (n meer andere, maken gebruik van de methode der statistick, echter alleen wanncer men het begrip in zijn ruimeve beteekenis neemt.

De beteekenis der algeneen-economisehe statistiek, zooals die hier te lande bestat, is nog van betrekkelijk geringe beteekenis roor de bedrijfsleiding.

Al wat deze statistick ons leert. leert de privat-economische ons sneller en beter.

Voor de bedrijfsleiding is de algemeen economische statistiek eerst van bizonder belung, wanneer zij meer bizonder wordt bowerkt tot cen conjunctuurstatistiek, welke niet allecn zoo moet zijn ingericht, dat rij het verloop der conjunctuur angect, maar ook moet zij zoo zijn samengestcle, dat zij aanwijzingen geeft voor de toekomstige conjunctuur-ontwikkeling.

En dat deze, bij de bedrijfsleiding in vele landen, in het teeken der allergrootste belan wstelling staat, blijkt uit de medewerking, welke conjunctuur-onderzock-instituten in het buitenland van versehillende zijden nit industrie, landbouw en handel mogen ondervinden, en inzonderheid hieruit, dat de Vel'eeniging van 'Textielfabrikanten in Saksen zelf cen conjunctuulonderzoekingsinstituut. in het leven riepen.

Van groot nut zijn ook onderzockingen, zooals door het Institut für Konjunkturforschung, te Berlijn, ingesteld naar den opslagduur en inkoopen in den goederenhandel, alsmede soortgelịke onderzoekingen ingesteld in Amerika.

De Nederlandsche huishouding, leent zich, met het oog op haar onderscheiden samenstclling en haar nauwen samenhang met de huishouding der omringende landen, misschien niet zoo goed voor degelijk onderzoek.

Hier echter ware ook reeds vecl op dit gebied te bereiken, en het Centraal-bureau voor de statistiek verdient aller belangstelling en medewerking in, zijn begonnen, pogingen, on tot dergelijke statistieken te komen.

Het belang der algemeen-economische statistiek sprak ook uit, de, te Genève onlangs gehouden, lntemationale Economische Conferentic; vooral in zijn resoluties over de Nijverheid, welke we, in de vertaling van het Centraal Bureau voor de statistick (Maandschrift Juni pag. 908) hier laten volgen.

I. De conferentie oordeelt:

$1^{\circ}$. dat voor een goede regeling en vol rendement der productic het bezit van samenvattende, doch nauwkenrige en geregeld bjjgehouden gegevens over grondstoffenvoorziening, over productie, voorraden, prijzen, loonen, stand der arbeidsmarkt. cnz., noodig is; $2^{\circ}$. dat het gewenscht is, dat deze gegevens in staat stellen voor elk land met voldoend ontwikkelde industrieën vergelijkbare, gewogen indexeijfers (d.z. indexcijfers waarbij de belangrijkheid der industrieën is in acht genomen, alsmede rekening is gehouden met bizondere invloeden. Opm. schr.) vast te stellen van de hoeveelheden goederen door de nijverheid van een land voortgebracht; $3^{\circ}$. dat dergelijke inlichtingen de juiste aanpassing van het aambod aan de vraag en de toepassing eener productiepolitick, welke de gevolgen van de schommelingen in de levendigheid van de markt vermindert, gemakkelijker maken. Verwijzend naar de resoluties welke de Economische Commissie van den Volkenbond (in haar ritting van 25 Febr, tot 2 Mrt. 1927) in dezen reeds nam, beveelt de Conferentie aan :

$1^{\circ}$. dat de statisticken van deze soort, zooveel mogelijk onder medewerking van do bevocgde organisaties, (zou ook de ace. org. hier mede zịn bedoeld met har kemnis van bedrijven en vedrijfsverloop? Opm. schr.) geregeld in alle landen verzameld worden voor de industrieën, wolke den grondslag vormen voor de wereldeconomie, en voorts - teneinde de samenstelling van gewogen indexeijfer's van de door de nationale nijverheid voortgebrachte goederen mogelijk te maken - voor de vool'naamste takken van nijverheid van elk land; $2^{\circ}$. dat de regeeringen periodiek volledige tellingen houden van de nijjverheid.

$2^{\circ}$. l)e conferentie is van meening, dat de practische waarde van deze statisticken afhangt van de vergelijkbaarheid en eenvormigheid der door elken stal verstrekte gegovens, en dat het gewenscht is, an deze inlichtingen alle noodige publieiteit te geven en ze uit een internationaal gezichtspunt te rangschikken on te gebruiken. Zij beveclt daarom aan:

10. Dat de Fconomische Commissie van den Volkenbond, alle passende maatregelen treffe, opdat de Regeeringen, in samenwerking met de belangrijkste industrieën, internationale overeenstemming tot stand brengen inzake de onschrijving der conomische beglippen, den volm en de wijze van samenstelling dezer" statistieken;

$2^{\circ}$. dat de Economische Commissie van den Volkenbond, die inlichtingen vrage, welke de herkomst on voorriening van grondstoffen, de productie, de voorraden, de prijzen, enz., be. treffen, en het Intermationaal Arbeidsbureau dic, aangadale de loonen, den arheirlsduur, den stand dev Arbeidsmarkt, enz.;

$3^{\circ}$. dat de Feonomische Commissie van den Volkenbond de noodige matregelen treffe voor de samenstelling van:

a. statistische en algeneene rapporten van intemationalen a ard over de organisehe ontwikkeling on den algemeenen toestand der versehillende takken van industrie, te borrinnen met de industrieën, welke den grondslag der wereldproductie vormen,

b. bizondere studies botreffende de mogelijkheid van voorziening in bepaalde soorten grondstoffen, met name die, waarvan verwacht kan worden, dat er in de toekomst een wereldtekort zal komen;

c. overzichten als die, welke reeds gepubliceerd werden, over de wijzigingen, welke in de productie en den wereldhandel voorkomen.

Tot hiertoe de conclusies.

We stappen nu hiermede af van de algemecn ceonomische statistick en hehandelen verder de privaat-economische.

Zooals misschien reeds gebleken is uit het vorenbehandelde wordt hier voornamelijk gehandeld over de statistick in de fabricksondermeming.

Vroeger onderscheidelen we reeds twee onderwerpen, waarop de statistiek betrekking had, n.l. interne en externe onderwerpen.

Daimaast moeten we onderseheid maken tussohen statis tieken wier geregeld bijzijn vereischt wordt, en statistieken wier bijwerlking periodick kan geschieden. Deze laatste groep is voor de dagelijksche leiding nict van zoo overwegend belang.

Schematisch voorgesteld krijgen we voor de statistick het volgende beeld (zic op de volgende bladzijcle).

Omtrent de onderscheiding in interne en externe statistiek meenen we voldoende gezegd te hebben.

De Dagclijksche-statistische boekhouding

Vele zullen er zijn, die deze boekhouding niet tot de statistiek gerekend willen zien.

Zooals wij in het begin van ons artikel opmerkten is dit verschil van meening van ondergeschikt belang.

Wij zullen hicr deze bockhouding behandelen.

De dagelijksche-statistische bockhouding moet aan de bedrïfsleiding uitsluitsel geven omtrent voorvallen en bewegingen, waarvan de kemnis dagelijks noodzakelijk is.

7ooals uit ons schema blijkt zijn dit:

I. machine-econonic, cl.i. de prestatie van de machines in het bedirijf.

Gewenseht is dagelijks hare productie te kemmen; de ecnvoudigste roorstelling van do normal capaciteit, is dan wol die, in \% afwijking van de normaalcapacitcit, daarbij rekening houdend met reparaties, e.a. de eigenlijke productiviteit niet 


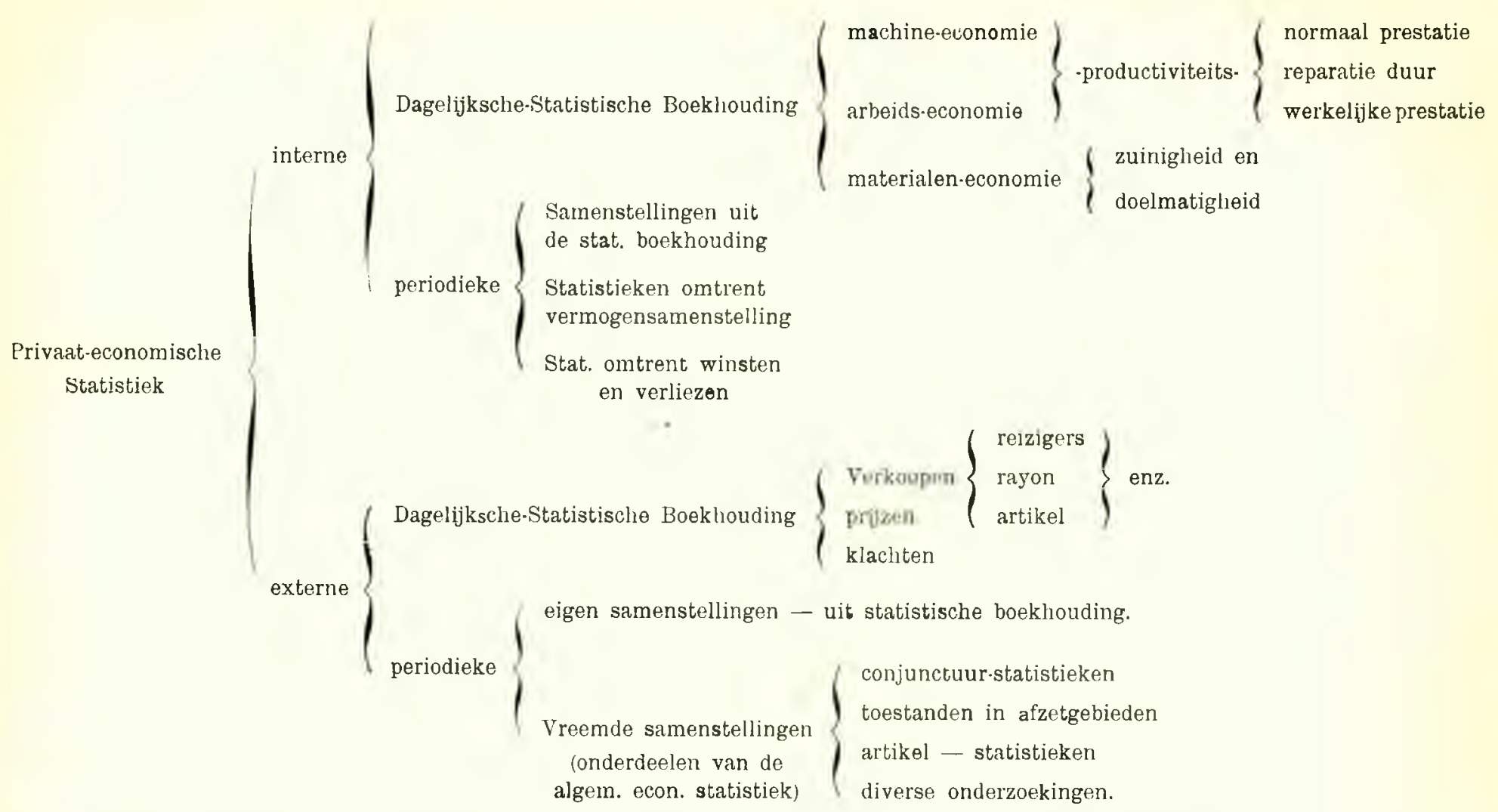

heinvloedende factoren. Vooral zij opgemerkt dat om een goede en doeltreffende statistiek voor de bedrijfscontrôle to kummen invoeren ecn normalisecring, en standaradiscering van bewerkingen en artikels, minstens tot zekere hoogte gewenscht is.

Telkens veranderingen maken, makt een statistick als hiel' bedoeld geheel onmogelijk, daar in zulke gevallen niet zịn vast te stellen productic ecnhoid en diensvolgens ook nict een normal prestatic. $\mathrm{Nu}$ kan men dan wel nemen de uren productieven arbeid; echter de productiviteit in die uren, verschilt. dan te veel, en het is juist die productiviteit die van bizonder belang is.

Tot op zeliere hoogte kan ook dan nog een statistiek worden sannengesteld.

Deze zou dan echter zoo uitgeloreid worden, dat ecn goed inzicht vrijwel onmogelijk is.

De normaliseering en standalardisecring is voor de verkrijging van een goede bedrijifseontrôle nu nict op te vatten als een noodzakelijk kwaad.

Juist gesproken is the zaak anrlersom ; n.l. de bedrijfscontrôle eiseht eene normaliseeling en standaardisecring, welke beide van het allergrootste nut zijn roor de verhooging der rentabiliteit, zoowel de physische d.w.z. productievermeerdering in hoeveclheid, als de financiëele d.w.z. verhooging van winsteijfer's, hoofdzakelijk loor liostenverlaging. T) term financieel hier is niet te verwaren met den in de bedrijfshuishoudkunde gebruikelijken term, financiëele rentabiliteit in tegenstelling met de economische lentabiliteit. waarbij de eerste bedoelt de rentabiliteit van het aandecl, bezien van het standpunt van den aandeelhouder, de tweede bedoelt de rentabiliteit bezien van het standpunt der onderneming, d.w.z. de rentabiliteit van het gehecle, in de onderneming belegde kapital (and. kap. + reserve (gcheine en andere) + vreemd kapitaal).

De statistische bockhouding over de machine omvat:

$1^{\circ}$. ean dagelijks bijgehouden overzicht over:

a. arbeidsduur in totaal,

b. reparaticluur,

c. werkelijken arbeidsduur, d. prestatic in productie-cenheden,

f. normanlprestatie,

$f$. afwijking in $\%-$ of -

1) krachtverbuik (werkelijke arbeidsduur X kracht in P.K.)

20. de bockhouding over verbruikte onderdeelen en onderhoudsuiddelen, en reparatiekosten.

Hierbij is van belang vergelijking tusschen dezelfde machines met verschillende arbeiders (arbeiderszuinigheid) (zic schema met matcrialen);

$3^{\circ}$. Oorzaken van afwijkingen tussehen normalal prestatie en breikte prestatie. Dit geschiedt alleen voor belangrijkere afwijkingen.

Jeze bockhouding geschiedt op kaarten.

be kaarten kumnen verder nog gebruikt worden voor eene kosten-cont rôle als volgt :

De kosten der machine worden op de kaart gebockt, gesplitst in constante en veranderlijke. De op orders verrekende kosten worden afgebockt. Zoo vindt men voor elke machine het verlies of de winst door minder of meer clan normale bezetting, hetgen voor de beoordeeling der juistheid der bedrijfsinrichting van zeer groot nut is. De kolom afwijking in \% min of plus, is de kolom welke voor de bedrijfsleiding zeer van belang is; ondat het nazien van deze betrekkelijk geen tijd kost, en direct gewezen wordt op plaatsen war machine-nren verspild worden.

De afwijkingen kumnen ook graphisch voorgesteld worden; cchter van groot nut zijn ze niet, waar hicr de cijfertabel evenzoo goed de vlugge illustrative geeft. Waartoe toch eigenlijk le grafische vonistelling dient. Straks wanneer we bij de periodicke statisticken komen, zullen we van de graphische voorstelling meer gebruik maken.

De statistick voor de ketelinstallatie eischt cen eenigszins anderen volm, en zal direct vereenigd moeten worden met de materialen-verbruiksstatistieken.

Ook bij de andere machines is vergelijking tusschen prestatic en verbruikte materialen noodig, ondat de qualiteit der mate- 
rialen van grooten invloed is op het werkelijke prestatievermogen der machine. 'Dit overzicht is echter' op eenvoudiger'wijze te berciken, n.l. wammeer een zekere soort materiaal geln'uikt is en men krijgt een steeds lagero werkelijke prestatic, ten opzichte van tijden, dat andere materialen gebruikt zijn, dan mag men cen oorzakelijk verband tusselien- die twee veronderstellen. Het vormen van juiste conclusies echter v'aagt hicr nauwkeuriger onderzoek en proefnemingen, ten einde den werkelijken invloed precies te kunnen vaststellen.

De statistick der ketelinstallatie moet zoo zijn ingericht dat blijkt :

$I^{\circ}$. bedrijfsduur,

$2^{\circ}$. stoker,

$3^{\circ}$. verbruikte brandst offen en andere materialen met qualiteit,

$4^{\circ}$. waterverbruik,

$5^{\circ}$. stoomdruk in atmosfcer,

$6^{\circ}$. opgewekte tonnen stoom,

$7^{\circ}$. tomnen stoom per K.G. kolen,

$8^{\circ}$. temperatuur en samenstelling der rookgasser,

$9^{\circ}$. Aan den ketel onttrokken stoom voor:

a. krachtmachine,

b. werktuigmachines,

c. werktuigmachines,

c. verwarming,

d. andere docleinden.

Hiertoe gebruike men stoommeters.

Ifet verbruik kan ook direct aan de desbetreffende verbruiksplaatsen vastgesteld worden.

Eenwel ter controleering van de stoomeondensatic in leidingen is gewenscht dubbcle vaststclling, n.l. aan ketel en aan de desbetreffende machines.

De krachtmachine-installatie, alsmede de electrische installatie, eischen eveneens cen dergelijk uitgebreid overzicht.

Verdere besprekingen van dit onderwerp zou ons te ver voeren op technisch tempein, warvan we liever afzien. Niet omdat het belang ervan zoo klein is. Verre van daar, en ook voor den accountant, die toch in zoo velerlei opzicht de raadsman der bedrijfsleiding moct zijn, is meer dan elementaire kennis, althans in zooverre controle en doelmatigheid betreft, van dit onderwerp noodig. We laten dit terrein erhter liever over aan meer - deskundigen.

We krijgen nu als tweede punt de statistische bockhouding over de arbeiders.

Deze zal omvatten:

$1^{\circ}$. arbeidsduur,

$2^{\circ}$. normaal prestatie,

$3^{\circ}$. werkelijke prestatic,

$4^{\circ}$. afwijking in + of - van normaal prestatic.

Daarnaast zal de dagelijksche loonboekhouding een plaats vinden, vooral wanneer het loonstelsel daartoe aanleiding geeft (Taylor-stelsel of variaties daarop; Emerson en Gant).

De moeilijkheid. ook hier, is weer de vaststelling van de juiste productie-eenheid, de basis van ecne dergelijlie statistisehe boekhouding.

In bedrijven met massaproductie is de vaststelling vrij eenvoudig. Specialiseering leiclt tot massaproductie; de specialiseering is hier dan ook zeer noodig, is in het grootbedrijf zelfs een eisch voor het succesvol voeren der leiding.

Eene volledige, uitvoerige bespreking van elk, in het schema aangegeven, onderdeel zou buiten het bestek van een tijodschriftartikel gaan.

We zullen daarom de punten verder maar slechts even aanstippen kumnen.

Nog mogen we wel even wijzen op het voordeel van een goede plan-afdeeling, voor de verkrijging van een geregeld productic- verloop, en een overzicht. der bezetting van nuchines, arbeider's en afdeclingen.

Dit overzicht kan tevens dienst doen als basis bij het zoeken naar orders.

Statistick in den eigenlijken zin is het nog minder dan de statistische boekhouding.

De statistische boekhouding ontrent materialen :

Deze moet aangevell:

$1^{\circ}$. Materiaalvoor'sad,

20. Materiaal-behoefte,

$3^{\circ}$. Materiaal-verbruik,

$4^{\circ}$. Verkregen resultaat met verbruik,

(heoordeeling der doelmatigheid en zuinigheid).

Daarnaast zullen plaatsvinden:

$5^{\circ}$. dagelijksche prijzenoverzichten,

$6^{\circ}$. geregeld bijgehouden leveranciersoverzicht,

$7^{\circ}$. geregeld overzicht van resultaten van proefnemingen.

l)e periodieke statistieken omvatten de samenvattingen der verkregen resultaten uit de dagelijksche boekhouding. Sommige gegevens eischen geene periodieke omwerking meer (resultaten van proefnemingen).

De periodicke samenvattingen zullen o.a. zijn:

$1^{\circ}$. productie, (totalal, artikelsgewijze, afdeelingsbezetting),

$2^{\circ}$. inkoopen, (materiaal verbruik, aard en doel),

$3^{\circ}$. arbeiders (totaal, afdeclingen, aard der werkzaamheden),

$4^{\circ}$. Opslagtermijn materialen,

$5^{\circ}$. kosten,

$6^{\circ}$. Verrekende kosten,

$7^{\circ}$. Verliezen en winsten door minder of meer dan normale bedrijfsbezetting, per machine, per afdeeling,

$8^{\circ}$. Winsten en verliezen uit productie, artikclsgewijze.

$9^{\circ}$. Samenstelling van het vermogen over:

a. vast en vlottend kapitaal,

b. eigen en vreemd kapitaal,

c. kapitaalbehoeften.

Verschillende dezer zullen graphisch kumen worden voorstcld. De graphische voorstelling zal hier het ovcrzicht, wal' het hier galat om een beweging, een verloop, of om een bepaald voorwerp, zeer' vergemakkelijken.

Tot hiertoc spraken we over de interne statistieken. Ons rest nog met een enkel woord te spreken over de externe statisticken.

De dagelijlksche-statistische boekhouding zal, zooals ons schema aangeeft, omvatten: verkoopen, prijzen, klachten. De verkoopen verdeeld naar afzetgebieden, naar artikelen en naar reizigers. Dit geschiedt in afzonderlijke staten (eventueel met gebruikmaking van een doorslag- of -schrijfsysteem), welke dagelijksch bijzij.jn.

Daarnaast worden dagelijks eveneens genoteerd de verkoopskosten (reclame, en andere kosten).

De dagtotalen zijn de cijfers, welke aan de bedrijfsleiding worden verstrekt in staten, die bevatten:

Orders ontrangen (als vorchaangegeven veldeeld), orders in uitvoering gegeven, vermoedelijken bezettingsduur (eventucel afdeclingsgewijze gesplitst), uitgevocrde orders, afgeleverd en eventueele bizonderheden.

Uit de dagelijks binnenkomende reisrapporten zal zooveel mogelijk geregeld en overzicht hijgehouden worden over, koopkracht, smaak, wenschen, stand concurrentie, en dergl., voor de versehillende afzetgebieden. Dit overzicht is van het allergrootste belang en wordt aangevuld uit, handelsberichten in diverso groote dagbladen en tijdschriften.

I) statistiek van de prijsbeweging omvat, de beweging der verkoopsprijzen van het eigen artikel, en de beweging der koopprijzen van de belangrijke materialen.

Dit prijsbewegingsoverzichit, straks vergeleken met conjunc- 
tumustatistieken, zal een op cen zekere correlatic tussehen prijs en eonjuncturr kunnen wịzen.

In periodieke opstollingen zijn de samenvattingen uit de staltistische boekhouding, met daumaast de graphisehe voorstelling orer kostmuijzen, winstmarges, en rerkoopprijzen der antikclen.

De reclannestatistick zal ook van bizonder helang zijn, in sommige fabricken (Margarinefabrieken, Tabaks- en Sigarenfabricken, enz.).

De reclamestatistick kan niet dagelijks bịj zịjn. Wel worden de gegerens verzameld; een af'zonderlijk doelmatige opstelling is later nog noodzakelijk. Bovendien een dagelijksch overzicht is hier noodzaliclijk incomplect, daar de resultaten del reclamecampague nict van dag tot dar te beordeelen ziju.

De statistick omvat:

$1^{\circ}$. kosten van

a. advertenticreclame,

b. radeaux reclame,

c. drukwerken reclame,

d. bizondere reclame.

20. Bewerkte gebied(n, walrgenomen resultaten,

$3^{\circ}$. Vergolijking der resultatem onderling der verschillende manieren ran reclamemaken en hun kosten.

De juiste beordecling der beschikbare gegevens over en reclamceampagne is zecr moeilijk, daar de hocgrootheid van versehillende invloeden bezwalarlijk kan worden vastgesteld.

Toch moet. met het oog op het groote belang, getracht wor(len, de statistick, zoo volledig mogelijk samen te stellen.

Omtrent de, als laatst in het schema genoemde, statistieken zij het volgende opgemerkt.

Ilet zijn over het algemcen statisticken, die om hum groot sociaal belang, door statistische buyeaux worden opgesteld. De boteekenis cl'van is zeer duidelijk. De gang van het bepaalde bedrijf vergelijkt men met den loop der eonjunetumbeweging, waruit cene bepaalde ontwikkcling van het bedijif roor de toekomst kan worden vastgesteld.

De diverse onderzoe,kingen hetreffen takken van nijverheid en zijn gericht op, mechanisatic, organisatic, opslagtermijnen (voorradirolming), wijze van verkoop (direct of indirect - uitschakeling - inschakeling), alle onderwerpen dic ook roor de afzonderlijke bedrijven van zecr groot belang zijn.

De normalgang der onderneming, zooals die is vastgesteld, kan vergeleken worden met den normaalgang der onderneming zooals die economisehe gerechtvaludigd is, een punt dat bij ale bepaling de normal productie en de darop te verrekenen kosten, zich alan de orde stelt.

\section{II. A. J. JANSSENS}

\section{COMPENSATIE VAN WINSTEN EN VERLIEZEN VOOR DE R.I.B}

1) Wet op de R.I.I3, gaat uit van het beginsel, dat het inkomen belast moet worden in het jaar, waarin het wordt genoten. Dit beginsel - nader uitgewerkt in de z.g. bromnentheoric - brengt medo, dat ran de bij den aanvang van het belasting.jar bestaande brommen van. inkomen begroot moet worden, wolk inkomen daaruit in den loop van dat jaar zal worden genoten. I)it sustcem is in da Wet op de R. I. B. consequent doorgeroerd. I al men hierbij van fieties gebruik maakt zooals h.v. deze, dat de begrooting meestal geschicdt door aan te nemen, dat de zuivere cphrengst over het latst verloopen kalender (hoek) jaar, ook in het komende belastingjaal zal wor'den genoten, doet aan het systeem als zoodanig prineipiecl niets af.

In dit systecm is plalats vool verrekening van winsten en verliczen, wanneer voor ééne bron ene negatieve- en voor eene andere bron eene positieve zuivere opbrengst wordt verkregen.

Ten aanzien van deze verrekening schrijft art. 17 voor:

„Wanneer ten aanzien cener bron van inkomen bij toepassing "del legelen ontrent de bepaling lep zuivere opbrengst een "verlies wordt verkregen, kont dit in mindering van de zui"vere opbrengst der verdere bromnen ran inkomen.

Compensatie heeft dus plaats van de resultaten van de bij den aanvang van het helastingjaar bestaande bronnen van inkomen en wol voor ieder belasting.jaar afzonderlijk. Eene verdere compensatic is nog mogelijk met een eventueel positief of negatief resultaat van op zich zelf stande werkzaamheden. Art. 18 schrijft voos, dat het saldo der berckening van art. 17 wordt vermeclelerd of verminderd met het voor- of nadeelig resultaat dezel" werkzadmheden. Na aftrek van de persoonlijke lasten van art. 19 wordt dan het belastbaar (zuiver) inkomen verkregen.

Zooals men rict liet de wet compensatie van verliezen met winsten van een volgend jaar niet toe. En terecht nict, want dit zou in strijd zijn met de bronnen-theorie en dus met het systeem der wet. Immers stat men eenmaal op het standpunt dat als inkomen roor een bepaald belastingjaar moet worden beschouwd de in dat jaar velmoedelijk te verkijigen opbrengst van de bij den aanvang ran dat jaar bestaande bronnen van inkomen, dan is darbij gecn plaats voor eene verrekening van verliezen over voorgande jaren. Dit komt al zeer duidelijk naar voren in het geval, dat zoo'n verliesgevende bron vóór den aanvang van het nieuwe belastingiadr voorgoed is gestaakt.

I iij het tot stand komen van de Wet op de R.J.B. is eene reruclijke compensatic dan ook afgewezen met een beroep op de onstandigheid, dat de belanghebbende dan toch over het laatstverloopen jaar cene winst heeft gemakt en dat het feit, dat hij een deel daarvan kun besteden tot het inhalen van zijn vroegor verlies geen reden kan zijph tot verlaging van belasting. Bij de wetswijziging van 28 April 1927 (Staatsblad No. 99) hecft men bovenbedoclde compensatic cehter toch in beperkte mate mogelijk gemaakt door ann art. 17 een nieuw (tweede) lid toe te voegen, luidende:

Indien en voor zoover verrekening van een verlies volgens ,het ecrste lid niet mogelijk is, heeft verrekening plats bij de ,vaststelling van het inkomen voor het volgend belastingjaar ,en indien en voor zoover zij ook dan niet kan plaats hebben, ,bij de vaststelling van het inkomen in het daarop volgend be"lastingjaar".

I) vraag is thans welke gevolgen verbonden zijn aan het inlasschen van deze net het systeem der wet strijdige bepaling.

T'wee punten zijn daarbịj van belang, n.l.:

1c. welk verlies kan voor compensatie in aanmerking komen; en

2c. waarmede moet dat verlies worden gecompenseerd.

Ten cincle lnet onderzoek te vergemakkelijken is uit de M. v. 'T', na te galan, welke bolocling feitclijk heeft voorgezeten en wat men eigenlijk voor compensatie in aanmerking wilde laten komen.

Ten aanzien van het moticf tot de ,frontverandering' zegt de M. v. T.

........dat degene die een bron van inkomen bezit, welke hem ,eell stcrk wisselende opbrengst, en zelfs zoo nu en dan een ,negratieve ophrengst bezorgt, zijne levenswijze zal instellen op ,een gemiddcld inkomen, waarbij hij ook de negatieve jaren ter,dege in anmerking neemt. Deze latste beschouwing moet , aammerkelijk in kracht winnen in de tegenwoordige tijden, nu ,slechte jaren veel minder dan vroeger tot de uitzonderingen "zijn gaan behooren" ...... 